\title{
The causal effect and impact of reproductive factors on breast cancer using super learner and targeted maximum likelihood estimation: a case-control study in Fars Province, Iran
}

\author{
Amir Almasi-Hashiani ${ }^{1,2}$, Saharnaz Nedjat ${ }^{3}$, Reza Ghiasvand ${ }^{4,5}$, Saeid Safiri ${ }^{6,7}$, Maryam Nazemipour ${ }^{8,9}$,
} Nasrin Mansournia ${ }^{10}$ and Mohammad Ali Mansournia ${ }^{11^{*}}$

\begin{abstract}
Objectives: The relationship between reproductive factors and breast cancer (BC) risk has been investigated in previous studies. Considering the discrepancies in the results, the aim of this study was to estimate the causal effect of reproductive factors on $\mathrm{BC}$ risk in a case-control study using the double robust approach of targeted maximum likelihood estimation.

Methods: This is a causal reanalysis of a case-control study done between 2005 and 2008 in Shiraz, Iran, in which 787 confirmed BC cases and 928 controls were enrolled. Targeted maximum likelihood estimation along with super Learner were used to analyze the data, and risk ratio (RR), risk difference (RD), andpopulation attributable fraction (PAF) were reported.

Results: Our findings did not support parity and age at the first pregnancy as risk factors for BC. The risk of BC was higher among postmenopausal women $(R R=3.3,95 \%$ confidence interval $(C I)=(2.3,4.6))$, women with the age at first marriage $\geq 20$ years $(R R=1.6,95 \% C l=(1.3,2.1))$, and the history of oral contraceptive $(O C)$ use $(R R=1.6,95 \%$ $\mathrm{Cl}=(1.3,2.1))$ or breastfeeding duration $\leq 60$ months $(\mathrm{RR}=1.8,95 \% \mathrm{Cl}=(1.3,2.5))$. The PAF for menopause status, breastfeeding duration, and OC use were $40.3 \%(95 \% \mathrm{Cl}=39.5,40.6), 27.3 \%(95 \% \mathrm{Cl}=23.1,30.8)$ and $24.4 \%(95 \%$ $\mathrm{Cl}=10.5,35.5)$, respectively.
\end{abstract}

Conclusions: Postmenopausal women, and women with a higher age at first marriage, shorter duration of breastfeeding, and history of $\mathrm{OC}$ use are at the higher risk of $\mathrm{BC}$

Keywords: Breast neoplasms, Reproductive history, Case-control study, Population attributable fraction, Causal analysis, Double robustness, TMLE, Super learner

\footnotetext{
* Correspondence: mansournia_ma@yahoo.com

${ }^{11}$ Department of Epidemiology and Biostatistics, School of Public Health, Tehran University of Medical Sciences, P.O Box: 14155-6446, Tehran, Iran

Full list of author information is available at the end of the article
}

C C The Author(s). 2021 Open Access This article is licensed under a Creative Commons Attribution 4.0 International License, which permits use, sharing, adaptation, distribution and reproduction in any medium or format, as long as you give appropriate credit to the original author(s) and the source, provide a link to the Creative Commons licence, and indicate if changes were made. The images or other third party material in this article are included in the article's Creative Commons licence, unless indicated otherwise in a credit line to the material. If material is not included in the article's Creative Commons licence and your intended use is not permitted by statutory regulation or exceeds the permitted use, you will need to obtain permission directly from the copyright holder. To view a copy of this licence, visit http://creativecommons.org/licenses/by/4.0/. The Creative Commons Public Domain Dedication waiver (http://creativecommons.org/publicdomain/zero/1.0/) applies to the data made available in this article, unless otherwise stated in a credit line to the data. 


\section{Highlights}

Postmenopausal women, women with higher age at marriage, women with lower breastfeeding duration, and women with a history of $\mathrm{OC}$ usage are at greater risk of $\mathrm{BC}$.

The most important risk and preventive factors were menopausal status and breastfeeding history, respectively.

Encouraging people to marry at a younger age, and increasing breastfeeding duration, as well as policies to reduce the use of hormonal contraceptives, can be effective in reducing $\mathrm{BC}$ cases.

\section{Introduction}

In previous decades, most cases of cancer have occurred in more developed countries, but recently the pattern has shifted towards developing or less-developed countries; these countries account for about $82 \%$ of the world's population, with about $57 \%$ of cancer cases and $65 \%$ of deaths from cancer [1]. According to GLOBOCAN, about 18.1 million new cases of cancer and 9.6 million deaths from cancer were reported in 2018 [2].

Breast Cancer (BC) has the highest number of incident cases [3]; it alone accounts for $25 \%$ of cancer cases and $15 \%$ of cancer deaths among women, with almost half of the new cases and $38 \%$ of deaths occurring in more developed countries $[1,4]$. It has the highest annual incidence among women in 161 countries and is also the leading cause of cancer death in 98 countries [5]. With 1.68 million cases in 2016, BC was reported as the most common cancer among women, with 535,000 deaths and 15.1 million DALYs [6]. About one-third of new cases of cancer among women is $\mathrm{BC}$ [7]. In recent years, the incidence and deaths from $\mathrm{BC}$ have increased in Asian countries including Iran $[1,3,6]$.

Several factors, such as smoking, being overweight, screening programs, physical inactivity, and changes in reproduction patterns associated with urbanization and economic development have contributed to the increase in the incidence of $\mathrm{BC}[1,2,8]$. Several studies have been carried out on the role of reproductive factors and contradictory results have been reported [9-16].

The causal study of the risk factors of $\mathrm{BC}$ requires careful adjustment for confounders. There are two broad approaches for confounding adjustment: conventional outcome regression modeling and propensity score methods (exposure modeling) [17]. The double-robust approach combines outcome and exposure models [18]. Misspecification of regression models may cause extreme bias in treatment effect estimates. This problem has led to a growing interest in using adaptive regression techniques, such as machine learning methods in causality research [19-22]. In particular, the field of targeted learning has emerged as a paradigm for wedding machine learning and formal statistical inference [23].

There are many methods for the causal analysis of case-control data, such as inverse probability-oftreatment weighting (IPTW), parametric g-formula (model-based standardization), and targeted maximum likelihood estimation (TMLE), all of which estimate the so-called marginal (population-averaged) causal effects [24-38]. The TMLE method is a combination of the IPTW and parametric g-formula and so is doublerobust: there are two possibilities for correct model specification [29].

The relationship between reproductive factors and risk of $\mathrm{BC}$ has been investigated in previous studies, but there were discrepancies in the reported results. Also to our best of knowledge, the causal effects of reproductive factors on $\mathrm{BC}$ have not been studied. Therefore, the aim of this study was to estimate the causal effect of reproductive factors on the risk of $\mathrm{BC}$ in a case-control study using TMLE [39] and Super Learner algorithms [39, 40] to adjust for confounders.

\section{Materials and methods Study design}

In this case-control study, frequency matching was performed by age, with five-year intervals. BC cases were confirmed by histopathology and their data were collected in the Cancer Registry Center of Shiraz University of Medical Sciences. This study was designed in 2005 and data were collected between September 2005 and December 2008 in Shiraz, Iran, and the available data were re-analyzed in 2018 (as PhD dissertation of the first author) in order to achieve more valid estimates, applying the advanced causal methods. The case data were collected from the main hospitals in Shiraz, covering over $85 \%$ of the incident cases in the city. In this study, more than $93 \%$ of the subjects were interviewed within a maximum of 6 months after diagnosing BC. The control group was selected from the Faqihi Hospital (as a general hospital) in Shiraz and from women without a history of $\mathrm{BC}$ or diseases with common risk factors with $\mathrm{BC}$ (such as gynecology, neoplasm, and hormonal disorders, and those referred to the skin clinic, internal medicine, and urology). Only participants with complete information (787 cases and 928 controls) for all variables were included. The study was approved in Tehran University of Medical Sciences (Code: 9121128009) in terms of methodology also by the Ethical Committee of Shiraz University of Medical Sciences (project number 591-2). All participants provided informed consent to be included in the study. Further details on the study design have been published [12, 41]. All methods were performed in accordance with the approved protocol as well as STROBE guideline. 


\section{Data gathering}

Variables were collected through interviewing by two nurses trained in the same way so that there is no heterogeneity in the data collection. A checklist (including socioeconomic, demographic, and reproductive factors) was used to collect relevant variables for BC.

\section{Variables}

Reproductive factors were identified as potential exposures, and anthropometric and socioeconomic factors as potential confounders. Reproductive variables, including parity $(\leq 3,>3)$, menopausal status (post-, premenopausal), age at first pregnancy $(<25, \geq 25$ years old), age at first marriage $(<20, \geq 20$ years old), history of breastfeeding duration $(\leq 60,>60$ months) and history of oral contraceptive (OC) use (ever, never), were considered as exposure variables and $\mathrm{BC}$ as the outcome.

Causal directed acyclic graphs (DAGs) [42-45] were used to identify the minimally sufficient set of confounders for effect of each exposure on the outcome (Supplementary Figures S1, S2, S3, S4, S5 and S6). In order to simplify the DAGs without loss of the validity of the back-door criterion, we avoided to present some arrows between covariates that did not play a role in identifying confounders. The causal relationship between variables (the arrows) was determined based on our prior knowledge and review of literature. The selection of which individuals to study (sampling) was influenced by their age (matched variables) and their disease status (case and control group), shown in the diagrams with arrows. In the figures, the variable $\mathrm{S}$ indicates selection of people from the hypothetical cohort into this casecontrol study (1:selected, 0: not selected). The arrows from $\mathrm{BC}$ and age to $\mathrm{S}$ reflect the age-frequency-matched case-control selection, and rectangle surrounding $\mathrm{S}=1$ indicates analysis is conditional on the selected individuals [46-48].

\section{Statistical analysis}

We used TMLE method to estimate the causal effect of reproductive factors on $\mathrm{BC}$. We estimated marginal risk difference (RD) and risk ratio (RR) as well as population attributable fraction (PAF) for the $\mathrm{BC}$ risk factors. We used a modification of TMLE appropriate for analyzing of case-control data, case-control weighted targeted maximum likelihood estimation (CCW-TMLE) $[29,30]$. Since sampling in case-control studies is biased with respect to the disease status i.e., the probability of selection for cases is much higher than that of controls [46, 47], CCW-TMLE is a weighted analysis. The weights were calculated as follows: The total number of $\mathrm{BC}$ women who were registered at the center was 1020 .As $85 \%$ of newly-diagnosed cases were referred to this center [41], over the period of the study, there were 1020/0.85=
1200 newly diagnosed patients in the province. Of these, 787 patients (with complete information) were entered into our study. Thus the sampling fraction of the case group was 787/1200 and the weight for cases will be $1200 / 787=1.5248$. The average population of women over 20 years old in the study period in Fars province was $1,346,630$. In this study, 928 women were selected as the control group. Thus, the sampling fraction of the control group is equal to $928 / 1,346,630$ and the weight for the control group will be 1,346,630/928 =1451.1.

The steps of CCW-TMLE are as follows:

Step 1: The case and control weights described above were assigned to cases and controls necessary due to the nature of the case-control study, to simulate a cohort study.

Step 2: The weighted conditional distribution of the outcome given exposure and confounders was estimated using super learning.

Step 3: The weighted conditional distribution of the exposure given confounders was estimated using super learning.

Step 4: A clever covariate, the inverse probability of exposure given confounders in the case group and the negative of the inverse probability of no exposure given confounders in the control group, was calculated.

Step 5: The outcome regression model from Step 2 was updated by adding the covariate described in step 4 , so that the coefficients of the model do not change. Step 6: The standardized mean outcome (e.g., risk) in the exposed group was calculated by predicting the individual mean outcome, for exposure forced to be 1 for all individuals, and the actual values of confounders, and then averaging them over the individuals from the model fitted in Step 5. Similarly, we calculated the standardized mean outcome (e.g., risk) in the unexposed group by predicting the individual mean outcome, for exposure forced to be 0 for all individuals, and the actual values of confounders, and then averaging them over the individuals from the model fitted in Step 5. Then we derived the RD, RR, and PAF. Step 7: The efficient influence curve (EIC) was used to estimate the standard error and compute Wald-type 95\% confidence intervals (CIs) [29, 30, 49].

In our study, PAF measures the proportion of $\mathrm{BC}$ (or any health-related outcome) that is attributable to a given exposure or the proportion of all $\mathrm{BC}$ cases that would not have occurred if the exposure has been removed [50, 51] and was calculated as follow [52]:

$$
\mathrm{PAF}=\frac{\mathrm{P}_{\mathrm{c}}(R R-1)}{R R}
$$


where $P_{c}$ stands for the prevalence of exposure in the case group. To calculate a 95\% CI for the PAF, a bootstrap confidence interval was used based on 10,000 bootstrap replicates and reporting the 2.5th and 97.5th percentiles.

\section{Statistical software}

Stata 14.0 (StataCorp LLC, College Station, Texas, USA) and R 3-4-3 software (R Foundation for Statistical Computing, Vienna, Austria) were used to perform the statistical analyses. The super learner packages glm, step, glm.interaction, randomForest, gam, rpart and glmnet algorithms were used. The codes used in the statistical analyses have been provided as a supplementary file for reproducibility (Appendix 1).

\section{Results}

The demographic variables have been described, separately for case and control groups, in Table 1 . The mean age in the case and control groups were $49.8(\mathrm{SD}=0.4)$ and $49.7(\mathrm{SD}=0.3)$ years, respectively $(p=0.8)$. The body mass index in the case group was higher than that in the control group (27.9 vs. $27.3 \mathrm{~kg} / \mathrm{m}^{2} ; p=0.001$ ).

As shown in Table 2, there was strong evidence of higher education level among the case group compared with the control $(p=0.001)$. Also, there was strong evidence that the frequency of being employed was higher in the case group than in the control group $(p=0.001)$, while there was no evidence regarding the difference in marital status between the two groups $(p=0.400)$. Moreover, the results of Table 2 support the higher prevalence of being postmenopausal, being older at first pregnancy, being older at first marriage, breastfeeding duration $<60$ months, history of OCP use and parity $\leq 3$ among case group than the control group.

The RR, RD, and PAF, obtained from the TMLE and super learner model, are presented in Table 3. There was no evidence of higher $\mathrm{BC}$ risk among women aged $\geq 25$ years at first pregnancy vs. women aged $<25$ years $(\mathrm{RR}=1.1,95 \% \mathrm{CI}=(0.6,1.7))$ and there was also no evidence that multiparity (parity>3) affects the risk of $\mathrm{BC}$ $(R R=1.1,95 \% C I=(0.8,1.5))$. On the other hand, there

Table 1 Comparison of demographic continuous variables by case-control status (787 cases and 928 controls) in Fars province, Iran, 2009

\begin{tabular}{llll}
\hline Characteristic & $\begin{array}{l}\text { Cases }(\boldsymbol{n}=\mathbf{7 8 7}) \\
\text { Mean (SD) }\end{array}$ & $\begin{array}{l}\text { Controls }(\boldsymbol{n}=\mathbf{9 2 8}) \\
\text { Mean (SD) }\end{array}$ & $\begin{array}{l}\boldsymbol{P} \text { - } \\
\text { value }^{\dagger}\end{array}$ \\
\hline Age (year) & $49.8(0.36)$ & $49.7(0.34)$ & 0.820 \\
Height $(\mathrm{cm})$ & $156.3(0.21)$ & $156.6(0.20)$ & 0.270 \\
Weight $(\mathrm{kg})$ & $68.3(0.42)$ & $66.9(0.39)$ & 0.010 \\
Body mass index & $27.9(0.16)$ & $27.3(0.15)$ & 0.001 \\
\hline
\end{tabular}

${ }^{\circ}$ Weight $(\mathrm{kg}) /$ height $^{2}\left(\mathrm{~m}^{2}\right) ;{ }^{\dagger}$ Obtained from independent t-test was strong evidence supporting a higher risk of $\mathrm{BC}$ among postmenopausal women $(\mathrm{RR}=3.3,95 \% \mathrm{CI}=(2.3$, 4.6)), women with age at first marriage $\geq 20$ years ( $R R=$ 1.6, $95 \% \mathrm{CI}=(1.3,2.1))$, and women with a history of OC use $(R R=1.6,95 \% \mathrm{CI}=(1.3,2.1))$. Furthermore, the history of lactation $\leq 60$ months had a significant effect on $\mathrm{BC}(\mathrm{RR}=1.8,95 \% \mathrm{CI}=(1.3,2.5))$ (Table 3 and Fig. 1$)$. The PAF for menopause status, breastfeeding duration, and history of OC use were $40.3 \%(95 \% \mathrm{CI}=39.5,40.6)$, $27.3 \%(95 \% \mathrm{CI}=23.1,30.8)$ and $24.4 \%(95 \% \mathrm{CI}=10.5$, $35.5)$, respectively.

\section{Discussion}

Using TMLE and super learner, we examined the causal relationship between reproductive factors and $\mathrm{BC}$ in a case-control study. The results showed no evidence of a causal relationship between parity or age at first pregnancy with the risk of $\mathrm{BC}$. However, menopausal status, age at first marriage, duration of breastfeeding, and history of OC use had causal effects on the risk of BC. PAF analysis suggested that menopausal status and breastfeeding duration have the most impact on the risk of BC in our study population. For instance, we found that $27.3 \%$ of $\mathrm{BC}$ cases in the population can be attributed to a history of breastfeeding duration $\leq 60$ months.

The findings of our study showed no evidence for less or higher risk of $\mathrm{BC}$ among multiparous women compared with women with fewer than or equal to three deliveries. A protective role of parity above three has also been reported in a meta-analysis study [15]. according to a study in Nigeria, parity was negatively correlated with the risk of $\mathrm{BC}$ [53].. In some other studies, parity has been shown to have a dual effect on $\mathrm{BC}$ so that in women under 45 years old parity was considered as a risk factor but in women over 45 years old parity has a protective role [16]. The results of a meta-analysis study have also shown that the risk of $\mathrm{BC}$ in women who have not yet given birth is $30 \%$ higher than that in women who have given birth, and the risk for every two births is reduced by $16 \%$ [54]. The results of the Antoniou et al. study [10] suggested that parity is a protective factor for $\mathrm{BC}$ among BRCA1 and BRCA2 notation carriers who were older than 40 years old.

Menopausal status had a strong causal relationship with $\mathrm{BC}(\mathrm{RR}=3.3,95 \% \mathrm{CI}:(2.3,4.6))$. Although the results of some studies were in agreement with our results, [13], the others indicated higher risk in premenopausal women in the same age groups [11]. Some of the differences in risk of $\mathrm{BC}$ between postmenopausal women and premenopausal women can be explained by differences in estrogen levels and age (if not adjusted) between the two groups [55].

Our study provided no evidence of higher BC risk in women with higher age at first pregnancy. The results of 
Table 2 Comparison of categorical variables by case-control status (787 cases and 928 controls) in Fars province, Iran, 2009

\begin{tabular}{|c|c|c|c|c|c|c|}
\hline \multirow[t]{2}{*}{ Characteristic } & & \multicolumn{2}{|c|}{$\begin{array}{l}\text { Cases } \\
(n=787)\end{array}$} & \multicolumn{2}{|c|}{ Controls $(n=928)$} & \multirow[t]{2}{*}{$\begin{array}{l}P \text { - } \\
\text { value }\end{array}$} \\
\hline & & $n$ & $\%$ & $n$ & $\%$ & \\
\hline \multirow[t]{4}{*}{ Education level } & Illiterate & 171 & 21.7 & 371 & 40.0 & 0.001 \\
\hline & Primary & 284 & 36.1 & 303 & 32.6 & \\
\hline & High-school & 239 & 30.4 & 217 & 23.4 & \\
\hline & Academic & 93 & 11.8 & 37 & 4.0 & \\
\hline \multirow[t]{2}{*}{ Occupation status } & Housewife & 635 & 80.7 & 873 & 94.1 & 0.001 \\
\hline & Employed & 152 & 19.3 & 55 & 5.9 & \\
\hline \multirow[t]{3}{*}{ Marital status } & Married & 665 & 84.5 & 777 & 83.7 & 0.440 \\
\hline & Divorced & 11 & 1.4 & 8 & 0.90 & \\
\hline & Widow & 111 & 14.1 & 143 & 15.4 & \\
\hline \multirow[t]{2}{*}{ Menopause status } & Pre-Menopausal & 330 & 41.9 & 476 & 51.3 & 0.001 \\
\hline & Post- Menopausal & 457 & 58.1 & 452 & 48.7 & \\
\hline \multirow[t]{2}{*}{ Age at first pregnancy (year) } & $<25$ & 613 & 77.9 & 831 & 89.55 & 0.001 \\
\hline & $\geq 25$ & 174 & 22.1 & 97 & 10.45 & \\
\hline \multirow[t]{2}{*}{ Age at first marriage (year) } & $<20$ & 478 & 60.7 & 713 & 76.8 & 0.001 \\
\hline & $\geq 20$ & 309 & 39.3 & 215 & 23.2 & \\
\hline \multirow[t]{2}{*}{ Breastfeeding duration (month) } & $\leq 60$ & 475 & 60.4 & 385 & 41.5 & 0.001 \\
\hline & $>60$ & 312 & 39.6 & 643 & 58.5 & \\
\hline \multirow[t]{2}{*}{ OC use } & Never & 280 & 35.6 & 397 & 42.8 & 0.002 \\
\hline & Ever & 507 & 64.4 & 531 & 57.2 & \\
\hline \multirow[t]{2}{*}{ Parity } & $\leq 3$ & 354 & 45.0 & 317 & 34.2 & 0.001 \\
\hline & $>3$ & 433 & 55.0 & 611 & 65.8 & \\
\hline
\end{tabular}

*Obtained from chi-square test

a study in Nigeria failed to show a relationship between age at first live birth and BC [53]. However, several previous studies indicate that low age at the first pregnancy reduces the risk of $\mathrm{BC}[12,13,15,54,56]$ so that the risk of $\mathrm{BC}$ has been reported twice among women whose first pregnancy was over 25 years [12]. Being older at first birth has been found to be associated with $\mathrm{BC}$ among BRCA2 but not for BRCA1 mutation [10]. The contradiction of our study findings with other studies may be justified by different confounders adjusted for in analysis and statistical methods used; TMLE method, along with the super learner approach, have been identified more efficient for controlling confounding [29, 30, 57].

Although our study suggested that marriage before 20 years old is protective for $\mathrm{BC}$, Ghiasvand et al. failed to demonstrate any relationship between age at first marriage and $\mathrm{BC}$ in young women [12]. Our findings are in line with the Kinlen study [58] in which risk of BC in women with age at first marriage and age at first birth

Table 3 The relationship between reproductive factors and breast cancer risk using TMLE and super learner approach (787 Cases, 928 Controls) in Fars province, Iran, 2009

\begin{tabular}{|c|c|c|c|}
\hline Reproductive factors & $\begin{array}{l}\text { Risk Differences }{ }^{a} \\
(95 \% \mathrm{Cl})\end{array}$ & $\begin{array}{l}\text { Risk ratio } \\
(95 \% \mathrm{Cl})\end{array}$ & $\begin{array}{l}\text { PAF (\%) } \\
(95 \% \mathrm{Cl})\end{array}$ \\
\hline Parity (> 3) & $6.6(-14.6,36.7)$ & $1.1(0.8,1.5)$ & $3.6(-8.5,20.2)$ \\
\hline Menopausal status (yes) & $69.4(68.0,70.0)$ & $3.3(2.3,4.6)$ & $40.3(39.5,40.6)$ \\
\hline Age at first pregnancy ( $\geq 25$ years) & $2.2(-33.6,38.1)$ & $1.1(0.6,1.7)$ & $1.16(1.16,1.17)$ \\
\hline Age at first marriage ( $\geq 20$ years) & $37.0(6.4,60.1)$ & $1.6(1.3,2.1)$ & $14.5(2.5,23.5)$ \\
\hline Breastfeeding duration $(\leq 60)$ & $45.3(38.4,51.1)$ & $1.8(1.3,2.5)$ & $27.3(23.1,30.8)$ \\
\hline OC use (yes) & $37.9(16.8,56.2)$ & $1.6(1.3,2.1)$ & $24.4(10.5,35.5)$ \\
\hline
\end{tabular}

Cl confidence interval, OC oral contraceptive, PAF population attributable fraction. ${ }^{a}$ per 100,000 


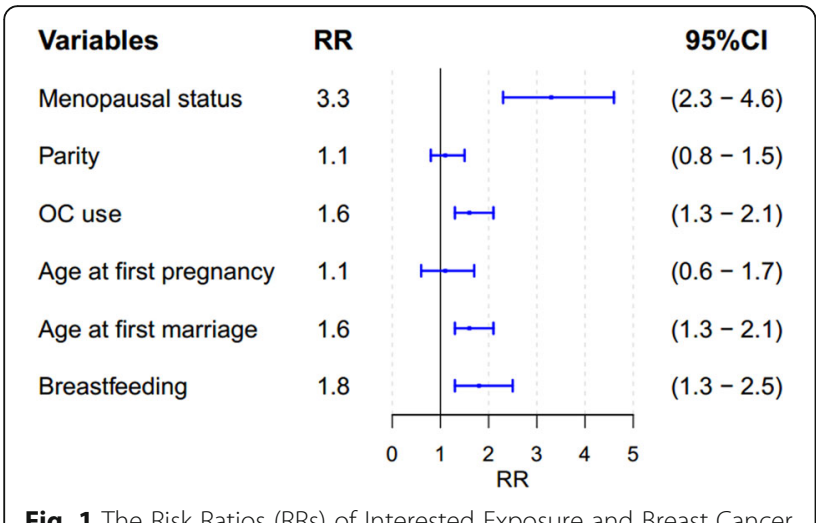

Fig. 1 The Risk Ratios (RRs) of Interested Exposure and Breast Cancer

30 years or older was 7 times compared to those with age at first marriage and age at first birth below 20 though he hypothesized that marriage involves the closest contact, pertinent to the infection, leading to an increase in various types of cancer [58, 59].

History of breastfeeding has been shown to be a protective factor for $\mathrm{BC}$ with a dose-response relationship, the risk is reduced with an increase in breastfeeding duration $[9,60]$, confirmed in our study. Generally, two mechanisms have been proposed for the protective effect of breastfeeding, the differentiation of breast tissue and the decrease in the number of ovulation cycles throughout life [61]. the result of a meta-analysis in 2008 demonstrated that only 11 out of the 24 published studies have reported a protective effect of breastfeeding on BC [61].

The history of $\mathrm{OC}$ use is considered to be a risk factor for BC as identified in a meta-analysis study by Anothaisintawee et al. [9]. Similarly, the risk in people with a history of $\mathrm{OC}$ use in our study was 1.6 times more than that in women without. In a Danish cohort study of 1.8 million women between the ages of 15 and 49, the risk ratio of $\mathrm{BC}$ for current and recent $\mathrm{OC}$ users was1.2, with more years of consumption, leading to a greater risk [14]. Conversely, some studies have reported any evidence for the effect of OC use on $\mathrm{BC}$ [15].

One of the strengths of our case-control study is applying the causal method of weighted TMLE, to identify risk factors of $\mathrm{BC}$, which unlike IPTW and parametric g-formula, is double robust. Using this methodology, we reported risk-based effect measures including, RD and RR as well as the impact measure of PAF. In addition, the super learner method has been employed to estimate the probability of outcome and exposure using a weighted linear combination of different algorithms instead of relying on a single algorithm, to improve the validity and efficiency of the effect estimate.

\section{Limitations}

Causal interpretation requires the measurement of all confounders, some of which may have been ignored in our study so the results should be considered with caution. Similar to all retrospective case-control studies, there was a potential for recall bias. Due to data collection between the September 2005 and December 2008, albeit the risk factors pattern is not expected to change significantly during one or two decades, it is recommended to externally validate the result of our study based on newer data.

\section{Conclusions}

In summary, postmenopausal women, women older at age of marriage, and women with the history of lower breastfeeding duration or $\mathrm{OC}$ use are at higher risk of $\mathrm{BC}$. The most important risk and preventive factors were menopausal status and history of breastfeeding duration, respectively. Further studies with a larger sample size and adjustment for a more complete set of confounders, particularly with regard to lifestyle factors, are warranted.

\section{Abbreviations}

BC: Breast Cancer; CCW-TMLE: Case-Control Weighted Targeted Maximum Likelihood Estimation; Cl: Confidence Interval; DAG: Directed Acyclic Graph; IPTW: Inverse Probability of Treatment Weighting; OC: Oral Contraceptive; PAF: Population Attributable Fraction; RR: Risk Ratio; RD: Risk Difference; TMLE: Targeted Maximum Likelihood Estimation

\section{Supplementary Information}

The online version contains supplementary material available at https://doi. org/10.1186/s12889-021-11307-5.

Additional file 1: Figure s1. A causal diagram representing the effect of parity on BC in the source population. Figure s2. A causal diagram representing the effect of breastfeeding on $B C$ in the source population. Figure s3. A causal diagram representing the effect of history of $O C$ usage on BC in the source population. Figure s4. A causal diagram representing the effect of menopausal status on $B C$ in the source population. Figure s5. A causal diagram representing the effect of age at first pregnancy on BC in the source population. Figure s6. A causal diagram representing the effect of age at first marriage on $B C$ in the source population.

Additional file 2: Appendix 1. Codes for Case Control Weighted TMLE (CCW-TMLE)

\section{Acknowledgements}

Thanks, and appreciation of Miguel-Angel Luque Fernandez who helped us with this study. We also thank the Tehran University of Medical Sciences for their help and all patients and staff of Shahid Motahari Breast Clinic in Shiraz.

\section{Authors' contributions}

MAM and $A A H, S N$ and RG designed the study and completed data collection and analyses. MAM, AAH, SN, RG, MN, NM and SS provided input into the study design and data collection materials. MAM and SN provided technical guidance. All authors have given a final approval of the version to be published. All authors have read and approved the final version of manuscript. 


\section{Funding}

The authors have not declared a specific grant for this research from any funding agency in the public, commercial or not-for-profit sectors.

\section{Availability of data and materials}

The data sets used and analyzed during the study are available from the corresponding author on reasonable request.

\section{Declarations}

\section{Ethics approval and consent to participate}

The study was approved in Tehran University of Medical Sciences (Code: 9121128009) in terms of methodology and was approved by the Ethical Committee of Shiraz University of Medical Sciences (project number 591-2) and also all participants provided informed consent to include in the study.

\section{Consent for publication}

Not applicable.

\section{Competing interests}

No potential conflicts of interest were disclosed.

\section{Author details \\ 'Department of Epidemiology, School of Health, Arak University of Medical Sciences, Arak, Iran. ${ }^{2}$ Traditional and Complementary Medicine Research Center, Arak University of Medical Sciences, Arak, Iran. ${ }^{3}$ Department of Epidemiology and Biostatistics, Knowledge Utilization Research Center, School of Public Health, Tehran University of Medical Sciences, Tehran University of Medical Science, Tehran, Iran. ${ }^{4}$ Department of Research, Cancer Registry of Norway, Oslo, Norway. ${ }^{5}$ Oslo Centre for Biostatistics and Epidemiology, Oslo University Hospital, Oslo, Norway. ${ }^{6}$ Aging Research Institute, Tabriz University of Medical Sciences, Tabriz, Iran. ${ }^{7}$ Department of Community Medicine, Faculty of Medicine, Tabriz University of Medical Sciences, Tabriz, Iran. ${ }^{8}$ Osteoporosis Research Center, Endocrinology and Metabolism Clinical Sciences Institute, Tehran University of Medical Sciences, Tehran, Iran. ${ }^{9}$ Psychosocial Health Research Institute, Iran University of Medical Sciences, Tehran, Iran. ${ }^{10}$ Department of Endocrinology, AJA University of Medical Sciences, Tehran, Iran. ${ }^{11}$ Department of Epidemiology and Biostatistics, School of Public Health, Tehran University of Medical Sciences, P.O Box: 14155-6446, Tehran, Iran.}

Received: 24 December 2020 Accepted: 15 June 2021

Published online: 24 June 2021

\section{References}

1. Torre LA, Bray F, Siegel RL, Ferlay J, Lortet-Tieulent J, Jemal A. Global cancer statistics, 2012. CA Cancer J Clin. 2015;65(2):87-108. https://doi.org/10.3322/ caac.21262.

2. Bray F, Ferlay J, Soerjomataram I, Siegel RL, Torre LA, Jemal A. Global cancer statistics 2018: GLOBOCAN estimates of incidence and mortality worldwide for 36 cancers in 185 countries. CA Cancer J Clin. 2018;68(6):394-424.

3. Alsharif U, El Bcheraoui C, Khalil I, Charara R, Moradi-Lakeh M, Afshin A, et al. Burden of cancer in the eastern Mediterranean region, 2005-2015: findings from the global burden of disease 2015 study. Int J Public Health. 2018; 63(1):151-64.

4. Fitzmaurice C, Dicker D, Pain A, Hamavid H, Moradi-Lakeh M, Maclntyre MF, et al. The global burden of cancer 2013. JAMA oncol. 2015;1(4):505-27. https://doi.org/10.1001/jamaoncol.2015.0735.

5. Global Burden of Disease Cancer C. Global, regional, and national cancer incidence, mortality, years of life lost, years lived with disability, and disability-adjusted life-years for 32 cancer groups, 1990 to 2015: a systematic analysis for the global burden of disease study. JAMA Oncol. 2017;3(4):524-48.

6. Fitzmaurice C, Akinyemiju TF, Al Lami FH, Alam T, Alizadeh-Navaei R, Allen $C$, et al. Global, regional, and National Cancer Incidence, mortality, years of life lost, years lived with disability, and disability-adjusted life-years for 29 Cancer groups, 1990 to 2016: a systematic analysis for the global burden of disease study. JAMA Oncol. 2018;4(11):1553-68. https://doi.org/10.1001/jama oncol.2018.2706.

7. Siegel RL, Miller KD, Jemal A. Cancer statistics, 2017. CA Cancer Journal Clin. 2017;67(1):7-30. https://doi.org/10.3322/caac.21387.
8. Pakzad R, Nedjat S, Yaseri M, Salehiniya H, Mansournia N, Nazemipour M, et al. Effect of smoking on breast Cancer by adjusting for smoking misclassification Bias and confounders using a probabilistic Bias analysis method. Clin Epidemiol. 2020;12:557-68. https://doi.org/10.2147/CLEP.S252 025.

9. Anothaisintawee T, Wiratkapun C, Lerdsitthichai P, Kasamesup V, Wongwaisayawan S, Srinakarin J, et al. Risk factors of breast Cancer:a systematic review and meta-analysis. Asia Pac J Public Health. 2013;25(5): 368-87. https://doi.org/10.1177/1010539513488795.

10. Antoniou AC, Shenton A, Maher ER, Watson E, Woodward E, Lalloo F, et al Parity and breast cancer risk among BRCA1 and BRCA2mutation carriers. Breast Cancer Res. 2006;8(6):R72. https://doi.org/10.1186/bcr1630.

11. Collaborative Group on Hormonal Factors in Breast C. Menarche, menopause, and breast cancer risk: individual participant meta-analysis, including 118964 women with breast cancer from 117 epidemiological studies. Lancet Oncol. 2012;13(11):1141-51.

12. Ghiasvand R, Maram ES, Tahmasebi S, Tabatabaee SHR. Risk factors for breast cancer among young women in southern Iran. Int J Cancer. 2011; 129(6):1443-9. https://doi.org/10.1002/ijc.25748.

13. Gibson LJ, Hery C, Mitton N, Gines-Bautista A, Parkin DM, Ngelangel C, et al. Risk factors for breast cancer among Filipino women in Manila. Int J Cancer. 2010;126(2):515-21. https://doi.org/10.1002/ijc.24769.

14. Mørch LS, Skovlund CW, Hannaford PC, Iversen L, Fielding S, Lidegaard $\varnothing$. Contemporary hormonal contraception and the risk of breast Cancer. $\mathrm{N}$ Engl J Med. 2017;377(23):2228-39. https://doi.org/10.1056/NEJMoa1700732.

15. Nelson HD, Zakher B, Cantor A, Fu R, Griffin J, O'Meara ES, et al. Risk factors for breast Cancer for women age 40 to 49: a systematic review and metaanalysis. Ann Intern Med. 2012;156(9):635-48. https://doi.org/10.7326/0003-4 819-156-9-201205010-00006.

16. Palmer JR, Wise LA, Horton NJ, Adams-Campbell LL, Rosenberg L. Dual effect of parity on breast cancer risk in African-American women. J Natl Cancer Inst. 2003;95(6):478-83. https://doi.org/10.1093/jnci/95.6.478.

17. Rosenbaum PR, Rubin DB. The central role of the propensity score in observational studies for causal effects. Biometrika. 1983;70(1):41-55. https:// doi.org/10.1093/biomet/70.1.41.

18. Kang JD, Schafer JL. Demystifying double robustness: a comparison of alternative strategies for estimating a population mean from incomplete data. Stat Sci. 2007;22(4):523-39.

19. Karim ME, Platt RW. Estimating inverse probability weights using super learner when weight-model specification is unknown in a marginal structural cox model context. Stat Med. 2017;36(13):2032-47. https://doi. org/10.1002/sim.7266.

20. Lee BK, Lessler J, Stuart EA. Improving propensity score weighting using machine learning. Stat Med. 2010;29(3):337-46. https://doi.org/10.1002/sim.3782.

21. van der Laan MJ. Targeted maximum likelihood based causal inference: Part I. Int J Biostat. 2010;6(2). https://doi.org/10.2202/1557-4679.1211.

22. Van Der Laan MJ, Rubin D. Targeted maximum likelihood learning. Int J Biostat. 2006;2(1). https://doi.org/10.2202/1557-4679.1043.

23. van der Laan MJ, Rose S. Targeted Learning in Data Science, vol. 10; 2017.

24. Abdollahpour I, Nedjat S, Mansournia MA, Sahraian MA, Kaufman JS. Estimating the marginal causal effect of fish consumption during adolescence on multiple sclerosis: a population-based incident case-control study. Neuroepidemiology. 2018:50(3-4):111-8. https://doi.org/10.1159/000487640.

25. Almasi-Hashiani A, Nedjat S, Mansournia MA. Causal methods for observational research: a primer. Arch Iran Med. 2018;21(4):164-9.

26. Mansournia MA, Altman DG. Inverse probability weighting. BMJ (Clinical research ed). 2016:352:1189.

27. Mansournia MA, Etminan M, Danaei G, Kaufman JS, Collins G. Handling time varying confounding in observational research. BMJ (Clinical research ed). 2017;359:j4587. https:/doi.org/10.1136/bmj.j4587.

28. Rose S. Causal inference for case-control studies. Berkeley: University of California; 2011.

29. Rose S, van der Laan M. A double robust approach to causal effects in casecontrol studies. Am J Epidemiol. 2014;179(6):663-9. https://doi.org/10.1093/a je/kwt318.

30. Schuler MS, Rose S. Targeted maximum likelihood estimation for causal inference in observational studies. Am J Epidemiol. 2017;185(1):65-73. https://doi.org/10.1093/aje/kww165.

31. Mansournia MA, Naimi Al, Greenland S. The implications of using lagged and baseline exposure terms in longitudinal causal and regression models. Am J Epidemiol. 2018;188(4):753-9. 
32. Mokhayeri Y, Hashemi-Nazari SS, Khodakarim S, Safiri S, Mansournia N, Mansournia MA, et al. Effects of hypothetical interventions on ischemic stroke using parametric G-formula. Stroke. 2019;50(11):3286-8. https://doi. org/10.1161/STROKEAHA.119.025749.

33. Abdollahpour I, Nedjat S, Almasi-Hashiani A, Nazemipour M, Mansournia MA, Luque-Fernandez MA. Estimating the Marginal Causal Effect and Potential Impact of Waterpipe Smoking on Multiple Sclerosis Using Targeted Maximum Likelihood Estimation Method: a Large PopulationBased Incident Case-Control Study. Am J Epidemiol. 2021; Online ahead of print.

34. Aryaie M, Sharifi H, Saber A, Nazemipour M, Mansournia MA. Longitudinal causal effects of normalized protein catabolic rate on all-cause mortality in patients with end-stage renal disease: adjusting for time-varying confounders using the G-estimation method. Am J Epidemiol. 2021;190(6): 1133-41. https://doi.org/10.1093/aje/kwaa281.

35. Khodamoradi F, Nazemipour M, Mansournia N, Yazdani K, Khalili D, Mansournia MA. The effects of smoking on metabolic syndrome and its components using causal methods in the Iranian population. Int J Prev Med. 2021; (in press).

36. Abdollahpour I, Nedjat S, Mansournia MA, Schuster T. Estimation of the marginal effect of regular drug use on multiple sclerosis in the Iranian population. PLoS One. 2018;13(4):e0196244. https://doi.org/10.1371/journal. pone.0196244

37. Almasi-Hashiani A, Mansournia MA, Rezaeifard A, Mohammad K. Causal effect of donor source on survival of renal transplantation using marginal structural models. Iran J Public Health. 2018;47(5):706-12.

38. Mansournia MA, Danaei G, Forouzanfar MH, Mahmoodi M, Jamali M, Mansournia N, et al. Effect of physical activity on functional performance and knee pain in patients with osteoarthritis : analysis with marginal structural models. Epidemiology. 2012;23(4):631-40. https://doi.org/10.1097/ EDE.0b013e31824cc1c3.

39. Van der Laan MJ, Rose S. Targeted learning: causal inference for observational and experimental data: Springer-Verlag New York: Springer Science \& Business Media; 2011. https://doi.org/10.1007/978-1-4419-9782-1.

40. Naimi Al, Balzer LB. Stacked generalization: an introduction to super learning. Eur J Epidemiol. 2018;33(5):459-64. https://doi.org/10.1007/s10654018-0390-z.

41. Ghiasvand R, Bahmanyar S, Zendehdel K, Tahmasebi S, Talei A, Adami HO, et al. Postmenopausal breast cancer in Iran; risk factors and their population attributable fractions. BMC Cancer. 2012;12(1):414. https://doi.org/10.1186/14 71-2407-12-414

42. Mansournia MA, Collins GS, Nielsen RO, Nazemipour M, Jewell NP, Altman DG, et al. A CHecklist for statistical Assessment of Medical Papers (the CHAMP statement): explanation and elaboration. British Journal of Sports Medicine. Online ahead of print. Published Online First: 29 January 2021. https://doi.org/10.1136/bjsports-2020-103651.

43. Etminan M, Brophy JM, Collins G, Nazemipour M, Mansournia MA. Curriculum in cardiology to adjust or not to adjust: the role of different covariates in cardiovascular observational studies. Am Heart J. 2021;237:627. https://doi.org/10.1016/j.ahj.2021.03.008.

44. Etminan M, Nazemipour M, Candidate MS, Mansournia MA. Potential Biases in Studies of Acid-Suppressing Drugs and COVID-19 Infection. Gastroenterology. 2021;160(5):1443-6.

45. Etminan M, Collins GS, Mansournia MA. Using causal diagrams to improve the design and interpretation of medical research. Chest. 2020;158(1s):S21s28. https://doi.org/10.1016/j.chest.2020.03.011.

46. Mansournia MA, Hernan MA, Greenland S. Matched designs and causal diagrams. Int J Epidemiol. 2013;42(3):860-9. https://doi.org/10.1093/ije/ dyt083.

47. Mansournia MA, Jewell NP, Greenland S. Case-control matching: effects, misconceptions, and recommendations. Eur J Epidemiol. 2018;33(1):5-14. https://doi.org/10.1007/s10654-017-0325-0,

48. Mansournia MA, Higgins JP, Sterne JA, Hernan MA. Biases in Randomized Trials: A Conversation Between Trialists and Epidemiologists. Epidemiology (Cambridge, Mass). 2017;28(1):54-9.

49. Mansournia MA, Nazemipour M, Naimi Al, Collins GS, Campbell MJ. Reflection on modern methods: demystifying robust standard errors for epidemiologists. Int J Epidemiol. 2021;50(1):346-51. https://doi.org/10.1093/ ije/dyaa260.

50. Mansournia MA, Altman DG. Population attributable fraction. BMJ (Clinical research ed). 2018;360:k757. https://doi.org/10.1136/bmj.k757.
51. Khosravi A, Nielsen RO, Mansournia MA. Methods matter: population attributable fraction (PAF) in sport and exercise medicine. Br J Sports Med. 2020;54(17):1049-54. https://doi.org/10.1136/bjsports-2020-101977.

52. Miettinen OS. Proportion of disease caused or prevented by a given exposure, trait or intervention. Am J Epidemiol. 1974;99(5):325-32. https:// doi.org/10.1093/oxfordjournals.aje.a121617.

53. Huo D, Adebamowo CA, Ogundiran TO, Akang EE, Campbell O, Adenipekun A, et al. Parity and breastfeeding are protective against breast cancer in Nigerian women. Br J Cancer. 2008;98(5):992-6. https://doi.org/10.1038/sj. bjc.6604275.

54. Ewertz M, Duffy SW, Adami HO, Kvale G, Lund E, Meirik O, et al. Age at first birth, parity and risk of breast cancer: a meta-analysis of 8 studies from the Nordic countries. Int J Cancer. 1990;46(4):597-603. https://doi.org/10.1002/ ijc.2910460408.

55. Li Y, Ambrosone CB, McCullough MJ, Ahn J, Stevens VL, Thun MJ, et al. Oxidative stress-related genotypes, fruit and vegetable consumption and breast cancer risk. Carcinogenesis. 2009;30(5):777-84. https://doi.org/10.1 093/carcin/bgp053.

56. Clavel-Chapelon F, Gerber M. Reproductive factors and breast cancer risk. Do they differ according to age at diagnosis? Breast Cancer Res Treat. 2002; 72(2):107-15. https://doi.org/10.1023/A:1014891216621.

57. Rose S. Mortality risk score prediction in an elderly population using machine learning. Am J Epidemiol. 2013;177(5):443-52. https://doi.org/10.1 093/aje/kws241.

58. Kinlen $\downarrow$. Breast cancer and ages at first marriage and first birth: a new hypothesis. Eur J Cancer Prev. 2014;23(1):53-7. https://doi.org/10.1097/CEJ. ob013e3283627ef5.

59. Kinlen L. Infections and immune factors in cancer: the role of epidemiology. Oncogene. 2004;23(38):6341-8. https://doi.org/10.1038/sj.onc.1207898.

60. Kim Y, Choi JY, Lee KM, Park SK, Ahn SH, Noh DY, et al. Dose-dependent protective effect of breast-feeding against breast cancer among everlactated women in Korea. Eur J Cancer Prev. 2007;16(2):124-9. https://doi. org/10.1097/01.cej.0000228400.07364.52.

61. Yang $L$, Jacobsen $\mathrm{KH}$. A systematic review of the association between breastfeeding and breast cancer. J Women's Health (Larchmt). 2008;17(10): 1635-45. https://doi.org/10.1089/jwh.2008.0917.

\section{Publisher's Note}

Springer Nature remains neutral with regard to jurisdictional claims in published maps and institutional affiliations.
Ready to submit your research? Choose BMC and benefit from:
- fast, convenient online submission
- thorough peer review by experienced researchers in your field
- rapid publication on acceptance
- support for research data, including large and complex data types
- gold Open Access which fosters wider collaboration and increased citations
- maximum visibility for your research: over $100 \mathrm{M}$ website views per year
At BMC, research is always in progress. 